\title{
Willingness to Pay for Social Health Insurance Among Teachers at Governmental Schools in Gondar Town, Northwest Ethiopia
}

This article was published in the following Dove Press journal: Risk Management and Healthcare Policy

\author{
Atalele Setegn' \\ Gashaw Andargie (D) ${ }^{2}$ \\ Getasew Amare $\mathbb{D D}^{2}$ \\ Ayal Debie $\mathbb{D}^{2}$
}

'University of Gondar Comprehensive and Specialized Referral Hospital, University of Gondar, Gondar, Ethiopia; ${ }^{2}$ Department of Health Systems and Policy, Institute of Public Health, College of Medicine and Health Sciences, University of Gondar, Gondar, Ethiopia

Correspondence: Ayal Debie University of Gondar, P.O. Box: 196,

Gondar, Ethiopia

Email debieayal@gmail.com
Background: Globally, about 1.3 billion people lack access to effective and affordable healthcare and 150 million people in 44 million households face financial catastrophe. Health insurance schemes are an effective financing mechanism to help people who are unable to use healthcare services. However, the government employee's Willingness to Pay (WTP) for the proposed premium for health insurance were not well investigated.

Methods: A facility-based cross-sectional study was conducted from April to May, 2018 among teachers at governmental schools of Gondar town. The participants were selected using a simple random sampling technique using their payroll list as a sampling frame. Data were cleaned, coded, and entered into EPI-INFO version 7 software and exported to SPSS version 20 for analysis. A $P$-value less than 0.05 and Adjusted Odds Ratio (AOR) with 95\% Confidence Interval (CI) were used to identify variables significantly associated with the outcome variable.

Results: Overall, $62.0 \%$ of teachers were willing to pay $3 \%$ or more of their monthly salary for SHI. In this study, teachers whose monthly salary was more than US\$215.6 (AOR=2.12; $95 \% \mathrm{CI}=1.07-4.17)$, first degree $(\mathrm{AOR}=4.44 ; 95 \% \mathrm{CI}=2.89-6.83)$, masters $(\mathrm{AOR}=4.91 ; 95 \%$ $\mathrm{CI}=1.14-11.09)$, history of illness in the past 6 months $(\mathrm{AOR}=2.13 ; 95 \% \mathrm{CI}=1.37-3.31)$, not facing difficulty covering medical bills $(\mathrm{AOR}=0.49 ; 95 \% \mathrm{CI}=0.35-0.84)$, heard about $\mathrm{SHI}$ $(\mathrm{AOR}=1.73,95 \% \mathrm{CI}=1.09-2.73)$, and favorable attitude towards SHI (AOR=1.82; 95\% $\mathrm{CI}=1.22-2.72$ ) were significantly associated with WTP for the proposed price of the scheme. Conclusion: The majority of teachers were WTP the proposed amount of premium for the scheme. Factors such as level of education, monthly salary, attitudes, difficulty of covering medical bills, information, and history of illness were significantly associated with WTP for SHI. Therefore, awareness creation (sensitization activities) about SHI and increasing the educational status of the participant could improve WTP.

Keywords: willingness to pay, social health insurance, teachers, Gondar town, Ethiopia

\section{Background}

Globally, about 1.3 billion people lack access to effective and affordable healthcare, and annually an additional 150 million people in 44 million households face financial catastrophe. ${ }^{1}$ Health insurance is a financial mechanism that allows individuals to protect themselves against the financial cost of illness by pooling risks with others in the population. ${ }^{2}$ Social health insurance is a universal insurance system financed by employee-employer-payroll deductions, and an equity fund from the government can also be created to supplement contributions for those 
whose pooling of resources for healthcare are not formally employed. ${ }^{3}$ Out-of-pocket spending is the major payment strategy for healthcare in most low- and middle-income countries. ${ }^{4}$ In the last decade low- and middle-income countries have made considerable progress towards the goal of Universal Health Coverage (UHC). 5,6

A survey report in Mongolia, Burkina Faso, and Uganda showed that about $5.5,15$, and $2.6 \%$ of households had been suffering from catastrophic health expenditures, respectively. ${ }^{7}$ At the micro-level, the total economic cost of illness for a family unit is estimated to be frequently above $10 \%$ of the household income. $^{8}$

The Ethiopian healthcare financing system highly depends upon out of pocket expenditure as a result of the absence of advanced methods to raise healthcare funds. ${ }^{9}$ The fifth national health account report of Ethiopia indicated that high household out of pocket health expenditure and low spending of government to healthcare could hamper poor households to access health services and put them at risk of impoverishment. ${ }^{10}$ In order to reduce the overdependence and direct payment, the governments should organize the way that the prepayment mechanism for the health services is rendered. The most common way of a prepayment mechanism is one that pools risk across the population through health insurance. ${ }^{11}$ Social Health Insurance (SHI) is one of several ways used to raise and pool funds for health financing. ${ }^{12}$ The principle of SHI is one of the most popularin developing countries and one of the main options for achieving UHC. ${ }^{13} \mathrm{SHI}$ is a mandatory type health insurance designed for civil servants who are working at formal sectors and payed through a payroll based system. It is financed by individuals and employers contributions. ${ }^{14,15}$ For the SHI scheme, many preparatory activities such as legislation, regulations, and draft packages were formulated. ${ }^{16,17}$ Following the legal frameworks, the health insurance agency was established in the Ministry of Health, and SHI was planned to be launched in July 2011, ${ }^{18}$ which was moved to $2014 .{ }^{19}$ Lack of sufficient information on demand and supply side implementation issues, limited management capacity, and low quality of services were among the challenges in the setup of the scheme. ${ }^{18,20}$ The original draft for the SHI strategy proposed a typical SHI package with a $3 \%$ of salary premium, with an exclusion for dialysis and dental care (except root canal) and services jointly provided by public and selected private providers. ${ }^{21}$

Studies indicate that $30 \%$ of households in South Africa, ${ }^{22} 90 \%$ of households in Ghana, ${ }^{23}$ and $87 \%$ of the uninsured respondents in Namibia, ${ }^{24}$ were willing to pay for health insurance schemes. In Ethiopia, studies indicate that $69.8 \%$ of civil servants in Debre Markos ${ }^{25}$ and $71.3 \%$ of teachers in Wolaita Sodo $^{16}$ are willing to pay the proposed premium (3\% of their salary) for SHI. Evidence shows that sociodemographic and economic, health and health-related awareness, knowledge, and attitude towards health insurance schemes determine the acceptance of SHI. ${ }^{16-21,24}$ Healthcare costs and out of pocket payment are very high in Ethiopia. Accordingly, SHI is one of the strategies to reduce OOP healthcare costs in Ethiopia. However, WTP for the proposed SHI was not well studied in the country, particularly in the study area. Therefore, this study aimed as assessing the WTP for SHI and associated factors among teachers in governmental schools in Gondar town, Northwest Ethiopia.

\section{Methods and Materials \\ Study Design and Settings}

An institution-based cross-sectional study design was conducted among teachers working in governmental schools of Gondar town from April to May 2018. The study was conducted in Gondar town which is one of the Multi-Politian towns in Amhara National Regional State in Northwest Ethiopia. Gondar town is found in the Northwest part of Ethiopia and it is 180 and $748 \mathrm{~km}$ from Bahir Dar (capital city of Amhara region) and Addis Ababa, respectively. Based on the 2007 Central Statics Agency (CSA) report of Ethiopia, the town had a total population of 400,000 . From these, 198,120 are males and 201,880 are females. ${ }^{26}$ The town had 23 kebeles and 48 health institutions. These are one comprehensive referral hospital, eight health centers, one private general hospital, 15 specialty clinics, 15 medium clinics, and eight primary clinics. The town also had 44 primary, six secondary, and five preparatory schools.

\section{Population and Sampling Procedure}

All teachers in Governmental schools in Gondar town were the source population. The study population were also all teachers in the selected governmental schools in Gondar town. Furthermore, all teachers who were served 6 months and above in the governmental schools of the town were included in the study, whereas those teachers who were absent during data collection were excluded from the study. 
The sample size for the first objective was calculated using the single population proportion formula with an assumption of the proportion of teachers WTP for the newly proposed SHI among teachers in Wolayita Sodo (53\%), ${ }^{16} 5 \%$ marginal error (d), 95\% level of confidence, 1.5 design effect and 5\% nonresponse rate. As a result, the final sample size for the first objective was 603 . Accordingly, the sample size for the second objective was calculated using a double population proportion formula using significant variables in previously conducted research in Wolayta Sodo, such as marital status, educational status, and heard about $\mathrm{SHI}^{16}$ and using an assumption of $95 \%$ level of confidence, $80 \%$ power, 1.5 design effect, and 5\% non-response rate. The sample sizes for the second objective were 155,164 , and 230 , respectively. These were less than that of the sample size for the first objective. Therefore, the final sample size was 603. Following sample size determination, the schools were stratified based on their levels as primary, secondary, and preparatory schools. The sample was proportionally allocated based on the number of teachers working in these schools. Finally, a simple random sampling technique was used to select the participants.

\section{Measurements and Variables}

Willingness to pay for SHI was the amount of premium (percentage of salary) which teachers were willing to pay for the scheme. Contingent Valuation Method (CVM) with double bounded dichotomous choice elicitation method was used to measure respondents' WTP for SHI with an initial bid of $3 \%$ of their monthly salary and participants who were willing to pay $3 \%$ or more of their monthly salary were considered as willing to pay for SHI. Knowledge of participants about the SHI scheme was measured by ten item questions each containing $(1=$ yes and $0=$ no) alternatives and those who had scored $60 \%$ or more of the total knowledge measuring score was considered as having good knowledge. Similarly, attitude towards SHI was also measured by six item questions each containing a five-point Likert Scale and those who scored $60 \%$ of the total attitude measuring score were considered as having a favorable attitude towards SHI. Additionally, the wealth status of participants was classified as low, middle, or high using principal component analysis.

\section{Data Collection Tools and Procedures}

A semi-structured self-administered questionnaire was used by reviewing different literature. ${ }^{16,25,27}$ The questionnaire had socio-demographic, economic status, health status, knowledge and attitude, and willingness to pay the scheme items. The questionnaire was prepared in English and then translated to Amharic and finally back to English by language experte to ensure consistency. Four diploma and two BSc degree graduated clinical nurses and health officers for data collectors and supervisors were recruited, respectively. One day of training was given for data collectors and supervisors. A pre-test was conducted among 30 teachers who were working at Debark town and some modification was made based on the pretest findings.

\section{Data Management and Analysis}

Data were entered and analyzed by using Epi Info version 7.2.1 and Statistical Package for Social Sciences (SPSS) version 20, respectively. Descriptive statistics such as percentage, frequency, mean, median, and standard deviation were presented using graphs and tables. A binary logistic regression model was fitted. Variables having a $p$-value of less than 0.2 during bi-variable logistic regression were entered in multiple logistic regression analysis. Finally, a $p$-value of less than 0.05 and an Adjusted Odds Ratio (AOR) with 95\% CI were used to declare factors associated with the outcome variable. Hosmer-Lemeshow goodness-of -fit test was done to check model fitness. Principal Component Analysis (PCA) was done for reduction of the factors that we used for measuring wealth status.

\section{Results \\ Socio-Economic and Demographic Characteristics}

A total of 574 teachers participated in the study with a response rate of $95.2 \%$. About $54.4 \%$ of participants were males and 93\% were Amhara. Furthermore, 81.9\% and $66.9 \%$ were orthodox Christians and married, respectively. The mean age of respondents was $26 \pm 9.2$ (SD) years. Additionally, $21.8 \%$ of teachers had a monthly salary of more than US\$215.6 and $34 \%$ of the respondents were classified as having high wealth status (Table 1).

\section{Knowledge and Attitude Towards SHI}

About $46 \%$ of participants had good perceived health status and $16 \%$ of respondents had chronic medical illness such as diabetes mellitus, hypertension, asthma, renal disease, liver disease, cardiac disease, and epilepsy. Thirty-five percent of teachers had a history of at least one episode of illness in the past 6 months, and $93.5 \%$ of them had got treatment. Onethird (33.6\%) of participants ever had faced difficulty of covering medical bills. More than eighty-five percent $(87.3 \%)$ of 
Table I Socio-Demographic Characteristics of Teachers in Governmental School at Gondar Town in Northwest Ethiopia, $2018(N=574)$

\begin{tabular}{|c|c|c|c|}
\hline Variables & Category & Frequency & $\%$ \\
\hline \multirow[t]{2}{*}{ Sex } & Male & 312 & 54.4 \\
\hline & Female & 262 & 45.6 \\
\hline \multirow[t]{4}{*}{ Age in years } & $<30$ & 44 & 7.7 \\
\hline & $30-39$ & 256 & 44.6 \\
\hline & $40-49$ & 145 & 25.3 \\
\hline & $\geq 50$ & 129 & 22.4 \\
\hline \multirow[t]{3}{*}{ Types of school } & Primary & 325 & 56.6 \\
\hline & Secondary & 143 & 24.9 \\
\hline & Preparatory & 106 & 18.5 \\
\hline \multirow[t]{3}{*}{ Religion } & Orthodox & 470 & 81.9 \\
\hline & Muslim & 79 & 13.8 \\
\hline & Protestant & 25 & 4.3 \\
\hline \multirow[t]{4}{*}{ Current marital status } & Married & 384 & 66.9 \\
\hline & Single & 119 & 20.7 \\
\hline & Divorced & 53 & 9.2 \\
\hline & Widowed & 18 & 3.1 \\
\hline \multirow[t]{2}{*}{ Family size } & $<5$ & 201 & 35.0 \\
\hline & $\geq 5$ & 373 & 65.0 \\
\hline \multirow[t]{2}{*}{ Under 5 Children } & Yes & 227 & 39.5 \\
\hline & No & 347 & 60.5 \\
\hline \multirow[t]{2}{*}{$>64$ years in household } & Yes & 36 & 6.5 \\
\hline & No & 538 & 95.3 \\
\hline \multirow[t]{3}{*}{ Educational status } & Diploma & 236 & 41 \\
\hline & Degree & 324 & 56.4 \\
\hline & Master & 14 & 2.4 \\
\hline \multirow[t]{3}{*}{ Experiences in years } & $\leq 5$ & 52 & 9.1 \\
\hline & $6-10$ & 102 & 17.8 \\
\hline & $\geq 11$ & 420 & 73.2 \\
\hline \multirow[t]{3}{*}{ Monthly salary (US\$) } & $<166.5$ & 162 & 28.2 \\
\hline & $166.5-215.6$ & 287 & 50.0 \\
\hline & $>215.6$ & 125 & 21.8 \\
\hline \multirow[t]{3}{*}{ Wealth status } & Low & 192 & 33.4 \\
\hline & Middle & 187 & 32.6 \\
\hline & High & 195 & 34.0 \\
\hline
\end{tabular}

teachers had heard about SHI and for more than half (53.4\%) of the participants their source of information was mass media. All respondents had no form of health insurance previously. Nearly sixty percent $(59.4 \%$ ) and $42.3 \%$ of respondents had good knowledge and favorable attitude towards SHI, respectively. Nearly half (49.3\%) of the participants had good perceived quality of healthcare services (Table 2).
Table 2 Knowledge, Attitude Towards SHI, and Health-Related Characteristics of Teachers at Governmental Schools of Gondar Town in Northwest Ethiopia, $2018(n=574)$

\begin{tabular}{|c|c|c|c|}
\hline Variables & Category & Frequency & $\%$ \\
\hline \multirow[t]{3}{*}{ Perceived health status } & Poor & 118 & 20.6 \\
\hline & Fair & 192 & 33.4 \\
\hline & Good & 264 & 46.0 \\
\hline \multirow{2}{*}{$\begin{array}{l}\text { History of chronic } \\
\text { illness }\end{array}$} & Yes & 92 & 16.0 \\
\hline & No & 482 & 84.0 \\
\hline \multirow{2}{*}{$\begin{array}{l}\text { History of illness in the } \\
\text { past } 6 \text { months }\end{array}$} & Yes & 345 & 60.1 \\
\hline & No & 229 & 39.9 \\
\hline \multirow[t]{2}{*}{ Treated } & Yes & 224 & 59.4 \\
\hline & No & 153 & 40.6 \\
\hline \multirow{3}{*}{$\begin{array}{l}\text { Where were you } \\
\text { treated? }\end{array}$} & Government & 117 & 49.8 \\
\hline & Private & 112 & 47.7 \\
\hline & Others & 6 & 2.6 \\
\hline \multirow[t]{3}{*}{$\begin{array}{l}\text { Methods of payment for } \\
\text { medical cost }\end{array}$} & $\begin{array}{l}\text { Out of } \\
\text { pocket }\end{array}$ & 212 & 90.6 \\
\hline & Borrowed & 18 & 7.7 \\
\hline & Free & 4 & 1.7 \\
\hline \multirow{2}{*}{$\begin{array}{l}\text { Difficulty of covering } \\
\text { medical bills }\end{array}$} & Yes & 193 & 33.6 \\
\hline & No & 381 & 66.4 \\
\hline \multirow[t]{2}{*}{ Attitude towards SHI } & Favorable & 243 & 42.3 \\
\hline & Unfavorable & 331 & 57.7 \\
\hline \multirow[t]{2}{*}{ Knowledge on $\mathrm{SHI}$} & Good & 341 & 59.4 \\
\hline & Poor & 233 & 40.6 \\
\hline \multirow[t]{2}{*}{ Heard about SHI } & Yes & 501 & 87.3 \\
\hline & No & 73 & 12.7 \\
\hline \multirow{5}{*}{$\begin{array}{l}\text { Source of information } \\
(n=50 I)\end{array}$} & Mass media & 268 & 53.4 \\
\hline & Friends/ & 98 & 19.6 \\
\hline & Colleagues & & \\
\hline & $\begin{array}{l}\text { Healthcare } \\
\text { providers }\end{array}$ & 87 & 17.4 \\
\hline & Others & 60 & 12.0 \\
\hline
\end{tabular}

\section{Willingness to Pay for SHI}

Sxity-two percent $(95 \% \mathrm{CI}=57.5-65.6)$ of teachers were willing to pay the proposed $\geq 3 \%$ of their monthly salary for the SHI scheme. Feelings of being healthy (31.7\%) and unable to pay (15.1\%) were some of the main reasons for unwillingness to pay for the scheme (Table 3).

\section{Factors Associated with WTP for SHI}

The results of this study showed that teachers who earned a monthly salary of USD $>215.6$ were 2.12-times 
Table 3 WTP for SHI ( $\geq 3 \%$ of Monthly Salary) Among Teachers in Governmental Schools at Gondar Town in Northwest Ethiopia, $2018(n=574)$

\begin{tabular}{|l|c|c|}
\hline Variables & Frequency & $\%$ \\
\hline WTP for SHI (3\% or more) & 356 & 62.0 \\
Yes & 218 & 38.0 \\
No & & \\
\hline Reasons for not willing to pay ( $=218)$ & 69 & 31.7 \\
Feeling of being healthy & 67 & 30.7 \\
Low perception of quality of healthcare & & \\
services & 33 & 15.1 \\
Unable to pay the premium & 32 & 14.7 \\
Inadequate benefit package & 17 & 7.8 \\
Prefer out of pocket & \\
\hline
\end{tabular}

$(\mathrm{AOR}=2.12 ; 95 \% \mathrm{CI}=1.07-4.17)$ more likely WTP for SHI compared with those who earned US $\$<166.5$ per month. Teachers who had a first degree were 4.44-times ( $\mathrm{AOR}=4.44 ; 95 \% \mathrm{CI}=2.89-6.83)$ and masters were 4.91times $\quad(\mathrm{AOR}=4.91 ; 95 \% \mathrm{CI}=1.14-11.09)$ more likely WTP for the scheme as compared to diploma holders. Participants who had a history of illness in the past 6 months were 2.13-times $(\mathrm{AOR}=2.13 ; 95 \% \mathrm{CI}=1.37-3.31)$ more likely WTP for SHI than their counterparts. Respondents who had no history of difficulty for covering medical bills were less likely willing to pay for the scheme by $51 \%(\mathrm{AOR}=0.49 ; 95 \% \mathrm{CI}=0.35-0.84)$ compared with those who had faced difficulty of covering medical bills. Participants who had ever heard about SHI were 1.73times (AOR $=1.73 ; 95 \% \mathrm{CI}=1.09-2.73)$ more likely willing to pay for SHI than their counterparts. Teachers who had a favorable attitude towards SHI were 1.82-times ( $\mathrm{AOR}=1.82 ; 95 \% \mathrm{CI}=1.22-2.72$ ) more likely willing to pay compared with those who had an unfavorable attitude (Table 4).

\section{Discussion}

The Health Care Financing (HCF) strategy named two generations of general healthcare reforms. These are: supply side issues (improvement of the availability and quality of services), and introduction of different health insurance schemes (SHI for formal and CBHI for informal sectors). ${ }^{28}$

This study revealed that about $62.0 \%(95 \% \mathrm{CI}=57.5-$ 65.6) of participants were willing to pay the proposed price of the scheme. This finding was lower than the studies done in Wolayta Sodo $(53 \%),{ }^{16}$ and Debre-
Markos $(68.9 \%),{ }^{29}$ Nigeria $(83.9 \%),{ }^{30}$ and Ghana $(90 \%) .{ }^{23}$ However, this finding was greater than the study done in Paulo's hospital, Addis Ababa (53\%). ${ }^{25}$ This might be due to the variation in study settings and because of information dissemination, accessibility, and burden of medical bills when seeking healthcare services. The possible explanation may be there is still a misconception in the willingness to pay about SHI. The possible reason might be difference in study areas, awareness, socioeconomic characteristics, wealth status, insurance experiences of study participants, and study population differences.

In this study, teachers who had earned a monthly salary of USD $>215.6$ were 2.12-times more likely WTP for SHI compared with those who earned USD $<166.5$ per month. This result is consistent with a study conducted in Bangladesh. ${ }^{31}$ This could be due to their ability to afford the health insurance premium. Teachers who had a first degree or masters were 4.44- and 4.91- times more likely WTP for the scheme, respectively, compared with diploma holders. This finding was in line with studies done in Bangladesh, ${ }^{31}$ North-Central Nigeria, ${ }^{8}$ and Wolayta Sodo. ${ }^{16}$ This might be due to the fact that people with higher education were more confident and trusting in a new system that could be attributed to accept the scheme positively. Furthermore, they might also have better knowledge about the benefits of making regular small health insurance payments to avoid the risk of catastrophic medical expenditures at the time of ill health.

Teachers who had a favorable attitude towards SHI were WTP for SHI scheme compared with their counterparts. This finding was consistent with a study conducted in Nigeria. ${ }^{32}$ This might be due to having a good attitude which will enhance individuals' preference to choose and use the SHI scheme. Participants who had ever heard about SHI were more WTP for SHI than their counterparts. This result was in line with the findings in Wolayta Sodo. ${ }^{16}$ The possible justification might be due to information dissemination about the program among beneficiaries which will improve the individuals' decision because of the advocacy of the government about the social health insurance scheme.

Respondents who had no history of difficulty for covering medical bills were less likely WTP for the scheme compared with those who had faced difficulty of covering medical bills. This result was consistent with a study conducted in China. ${ }^{27}$ The possible explanation might be employees from the public sector are not assisted in 
Table 4 Factors Associated with WTP for SHI Among Teachers in Governmental Schools at Gondar Town, Northwest Ethiopia, 2018 $(n=574)$

\begin{tabular}{|c|c|c|c|c|}
\hline \multirow[t]{2}{*}{ Variables } & \multicolumn{2}{|c|}{ WTP to SHI } & \multirow[t]{2}{*}{ COR $(95 \% \mathrm{Cl})$} & \multirow[t]{2}{*}{ AOR $(95 \% \mathrm{Cl})$} \\
\hline & Yes & No & & \\
\hline \multicolumn{5}{|c|}{ Level of education } \\
\hline Diploma & 91 & 145 & 1 & 1 \\
\hline Degree & 254 & 70 & $5.78(3.98-8.39)$ & $4.44(2.89-6.83)^{*}$ \\
\hline Master & 11 & 3 & $5.84(1.58-13.50)$ & $4.91(1.14-11.09)^{*}$ \\
\hline \multicolumn{5}{|c|}{ Monthly salary (US\$) } \\
\hline$<166.5$ & 66 & 96 & $\mathrm{I}$ & 1 \\
\hline $166.5-215.6$ & 191 & 96 & $2.89(|.94-4.3|)$ & $1.50(0.94-2.40)$ \\
\hline$>215.6$ & 99 & 26 & $5.54(3.25-9.44)$ & $2.12(1.07-4.17)^{*}$ \\
\hline \multicolumn{5}{|l|}{ Family size } \\
\hline$\leq 5$ & 106 & 95 & $0.55(0.34-0.90)$ & $0.74(0.42-1.3 \mathrm{I})$ \\
\hline$>5$ & 250 & 123 & 1 & 1 \\
\hline \multicolumn{5}{|c|}{ Heard about SHI } \\
\hline Yes & 320 & 181 & $1.82(1.43-3.14)$ & $1.73(1.09-2.73)^{*}$ \\
\hline No & 36 & 37 & 1 & 1 \\
\hline \multicolumn{5}{|c|}{ Difficulty of covering medical bills } \\
\hline Yes & 137 & 56 & 1 & 1 \\
\hline No & 219 & 162 & $0.55(0.38-0.80)$ & $0.49(0.35-0.84)^{*}$ \\
\hline \multicolumn{5}{|l|}{ Sex } \\
\hline Male & 204 & 108 & 1 & 1 \\
\hline Female & 152 & 110 & $0.73(0.52-1.03)$ & $0.99(0.67-1.48)$ \\
\hline \multicolumn{5}{|c|}{ Attitude towards SHI } \\
\hline Favorable & 163 & 80 & $1.46(1.31-2.89)$ & $1.82(1.22-2.72)^{*}$ \\
\hline Unfavorable & 193 & 138 & 1 & 1 \\
\hline \multicolumn{5}{|c|}{ Hx of illness in the last 6 months } \\
\hline Yes & 228 & 117 & $1.54(1.12-2.23)$ & $2.13(1.37-3.31)^{*}$ \\
\hline No & 128 & 101 & 1 & 1 \\
\hline \multicolumn{5}{|c|}{ History of chronic illness } \\
\hline Yes & 42 & 50 & $0.45(0.23-1.49)$ & $0.66(0.97-3.86)$ \\
\hline No & 314 & 168 & 1 & 1 \\
\hline
\end{tabular}

Note: *Significant at $P$-value $<0.05$.

organizing their healthcare. Consequently, they use the out-of-pocket payment system to cover their health bills. At last, participants who had a history of illness in the past 6 months were 2-times more likely WTP for SHI than heir counterparts. This study finding was consistent with willingness to pay for health insurance technology in Ethiopia. ${ }^{33}$ This could be due to the fact that people with poor health and chronic illness have greater perceived risk of care seeking and then a strong need to pay the SHI scheme. The limitation of this study was the possibility of bias (hypothetical bias) related to the contingent valuation method. The strength of this study is the assessment of perception of teachers for this newly proposed SHI is before its implementation is suggestive for changing the strategy into action.

\section{Conclusion}

The majority of teachers were willing to pay the proposed amount of premium. Factors such as level of education, monthly salary, attitudes towards SHI, difficulty of covering medical bills, heard about SHI, and history of illness in the past 6 months were significantly associated with teachers' willingness to pay for social health insurance. Therefore, awareness creations (sensitization activities) about SHI scheme, 
enhancing educational status and promotion on attitudinal changes might need to improve their willingness to pay on SHI.

\section{Abbreviations}

CBHI, Community Based Health Insurance; CI, Confidence Interval; CVM, Contingent Valuation Method; ETB, Ethiopian Birr; GDP, Gross Domestic Product; OOP, OutOf-Pocket; SPSS, Statistical Package for Social Science; SHI, Social Health Insurance; WTP, Willingness to Pay.

\section{Data Sharing Statement}

All the data supporting the findings are within the manuscript. Additional detailed information and raw data are available from the corresponding author on reasonable request.

\section{Ethics Approval and Consent to Participate}

This study was conducted in accordance with the Declaration of Helsinki. Ethical clearance was obtained from the Ethical Review Committee of Institute of Public Health, College of Medicine and Health Sciences, University of Gondar. Written informed consent was taken from each participant. Moreover, verbal informed consent was obtained from those participants who could not read and write, approved by the ethical committee. Each eligible participant was informed about the purpose of the study. Participants were also assured that their name was not written on the questionnaire and confidentiality was kept at all levels.

\section{Acknowledgments}

The authors would like to thank the Institute of Public Health, College of Medicine and Health sciences, University of Gondar for giving the opportunity to study in this area. This manuscript is part of master thesis work for the principal investigator. Furthermore, our gratitude goes to Gondar town administration educational offices for their cooperation. Finally, we would like thank the participants and data collectors for their contribution in the study.

\section{Author Contributions}

All authors made substantial contributions to the conception and design, acquisition of data, or analysis and interpretation of data; took part in drafting the article or revising it critically for important intellectual content; agreed to submit to the current journal; gave final approval of the version to be published; and agree to be accountable for all aspects of the work.

\section{Funding}

This study was sponsored by the principal investigator.

\section{Disclosure}

The authors declare that there are no conflicts of interest in this work.

\section{References}

1. World Health Organization. Designing health financing systems to reduce catastrophic health expenditure. Geneva: World Health Organization; 2005.

2. Comfort AB, Peterson LA, Hatt LE. Effect of health insurance on the use and provision of maternal health services and maternal and neonatal health outcomes: a systematic review. J Health Popul Nutr. 2013;31(4 Suppl 2):81-105.

3. Usoroh EE. Amsterdam: achieving universal health coverage in Nigeria: the national health insurance scheme as a tool. Vrije Universiteit Amsterdam; 2012.

4. Ahmed S, Hoque ME, Sarker AR, et al. Willingness-to-pay for community-based health insurance among informal workers in Urban Bangladesh. PloS One. 2016;11(2)

5. Alkenbrack S, Hanson K, Lindelow M. Evasion of "mandatory" social health insurance for the formal sector: evidence from Lao PDR. BMC Health Serv Res. 2015;15(1).

6. Vuong QH. Be rich or don't be sick: estimating Vietnamese patients' risk of falling into destitution. SpringerPlus. 2015;4(1):1-31. doi:10.1186/s40064-015-1279-x

7. Russell S. The economic burden of illness for households in developing countries: a review of studies focusing on malaria, tuberculosis, and human immunodeficiency virus/acquired immunodeficiency syndrome. Am J Trop Med Hyg. 2004;71(2_suppl):147-155. doi:10.4269/ajtmh.2004.71.147

8. Babatunde O, Akande T, Salaudeen A, Aderibigbe S, Elegbede O, Ayodele L. Willingness to pay for community health insurance and its determinants among household heads in rural communities in North-Central Nigeria. Int Rev Soc Sci Humanities. 2012;2(2):133-142.

9. Richard G. Reviewing Ethiopia's health system development. JMAJ. 2009;52(4):279-286.

10. Federal Ministory of Health (FMOH). Ethiopia's fifth national health accounts highlight of major findings. Addis Ababa; April, 2014. Available from: https://www.hfgproject.org/wp-content/uploads/ 2014/04/Ethiopia-NHA-Findings-Briefing-Notes.pdf. Accessed February 24, 2021.

11. World Health Organization. The world health report: health systems financing: the path to universal coverage: executive summary. Geneva: World Health Organization; 2010.

12. Doetinchem O, Carrin G, Evans D. Thinking of introducing social health insurance? Ten questions. World Health Rep. 2010.

13. Rannan-Eliya R, Irava W, Saleem S. Assessment of social health insurance feasibility and desirability in Fiji. Suva: Ministry of Health and World Health Organization; 2013.

14. Carrin G, James C. Social health insurance: key factors affecting the transition towards universal coverage. Int Soc Secur Rev. 2005;58 (1):45-64. doi:10.1111/j.1468-246X.2005.00209.x

15. Ogawa S, Hasegawa T, Carrin G, Kawabata K. Scaling up community health insurance: Japan's experience with the 19th century Jyorei scheme. Health Policy Plan. 2003;18(3):270-278. doi:10.1093/hea$\mathrm{pol} / \mathrm{czg} 033$ 
16. Agago TA, Woldie M, Ololo S. Willingness to join and pay for the newly proposed social health insurance among teachers in Wolaita Sodo town, South Ethiopia. Ethiop $J$ Health Sci. 2014;24 (3):195-202. doi:10.4314/ejhs.v24i3.2

17. Nosratnejad S, Rashidian A, Dror DM. Systematic review of willingness to pay for health insurance in low and middle income countries. PLoS One. 2016;11(6):e0157470. doi:10.1371/journal. pone. 0157470

18. Abel-Smith B. Employer's willingness to pay: the case for compulsory health insurance in Tanzania. Health Policy Plan. 1994;9 (4):409-418. doi:10.1093/heapol/9.4.409

19. Khan JA. Impact of education on informal workers willingness-topay and knowledge of health insurance. Res Paper. 2012;16.

20. Molla A, Fentahun N. Predictors of willingness to participate in health insurance services among the community of Jimma town, Southwest Ethiopia. Health Serv Insights. 2014;7(HSI):S18046. doi:10.4137/HSI.S18046

21. Obse A, Hailemariam D, Normand C. Knowledge of and preferences for health insurance among formal sector employees in Addis Ababa: a qualitative study. BMC Health Serv Res. 2015;15(1):1-11. doi:10.1186/s12913-015-0988-8

22. Shisana O, Rehle T, Louw J, Zungu-Dirwayi N, Dana P, Rispel L. Public perceptions on national health insurance: moving towards universal health coverage in South Africa. South Afr Med J. 2006;96(9):814-818.

23. Asenso-Okyere WK, Osei-Akoto I, Anum A, Appiah EN. Willingness to pay for health insurance in a developing economy. A pilot study of the informal sector of Ghana using contingent valuation. Health Policy. 1997;42(3):223-237. doi:10.1016/S01688510(97)00069-9

24. Gustafsson-Wright E, Asfaw A, van der Gaag J. Willingness to pay for health insurance: an analysis of the potential market for new low-cost health insurance products in Namibia. Soc Sci Med. 2009;69(9):1351-1359. doi:10.1016/j.socscimed.2009.08.011
25. Lasebew Y, Mamuye Y, Abdelmenan S. Willingness to pay for the newly proposed social health insurance among health workers at St. Paul's Hospital Millennium Medical College, Addis Ababa, Ethiopia. Int J Health Econ Policy. 2017;2(4):159.

26. CSA Ethiopia. Summary and statistical report of the 2007 population and housing census. Addis Ababa, Ethiopia: Federal democratic republic of Ethiopia population census commission; 2008.

27. Bärnighausen T, Liu Y, Zhang X, Sauerborn R. Willingness to pay for social health insurance among informal sector workers in Wuhan, China: a contingent valuation study. BMC Health Serv Res. 2007;7:114. doi:10.1186/1472-6963-7-114

28. MOH. Health care financing strategy. Addis Ababa: Federal Ministry of Health; 1998.

29. Elaynesh Abebaw DJ. Tarkegn Asmamaw and Tenaw Chanie willingness to pay for the newly proposed social health insurance scheme and associated factors among civil servants in Debre Markos Town, North West Ethiopia. MRCR. 2015;2(2).

30. Osungbade KO, Olumide A, Balogun O, Famakinwa EO, Jaiyeoba O. Social health insurance in nigeria: policy implications in a rural community. Niger Med Pract. 2010;57(5-6):5-6. doi:10.4314/nmp. v57i5-6.57840

31. Ahmed S, Hoque ME, Sarker AR, et al. Willingness-to-pay for community-based health insurance among informal workers in Urban Bangladesh.pdf. PLoS One. 2016;11:e0148211. doi:10.1371/ journal.pone. 0148211

32. Adewole DA, Adebayo AM, Osungbade KO. A qualitative survey of pre-payment scheme for healthcare services in a Rural Nigerian Community. Af J Biomed Res. 2017;20:17-24.

33. Entele BR, Emodi NV. Health insurance technology in Ethiopia: willingness to pay and its implication for health care financing. Am J Public Health Res. 2016;4:98-108.
Risk Management and Healthcare Policy

\section{Publish your work in this journal}

Risk Management and Healthcare Policy is an international, peerreviewed, open access journal focusing on all aspects of public health, policy, and preventative measures to promote good health and improve morbidity and mortality in the population. The journal welcomes submitted papers covering original research, basic science, clinical \& epidemiological studies, reviews and evaluations, guidelines, expert opinion and commentary, case reports and extended reports. The manuscript management system is completely online and includes a very quick and fair peer-review system, which is all easy to use. Visit http://www.dovepress.com/testimonials.php to read real quotes from published authors. 